\title{
Trpc6 Promotes Doxorubicin-Induced Cardiomyopathy in Male Mice With Pleiotropic Differences Between Males and Females
}

\section{OPEN ACCESS \\ Edited by: \\ Chen Yan, \\ University of Rochester, United States}

Reviewed by:

Lei Xi,

Virginia Commonwealth University,

United States

Hui-Hua Li,

Capital Medical University, China

*Correspondence:

DeLisa Fairweather

Fairweather.DeLisa@mayo.edu

Nadine Norton

Norton.Nadine@mayo.edu

tThese authors have contributed equally to this work and share first

authorship

¥These authors have contributed equally to this work and share senior authorship

Specialty section:

This article was submitted to

Cardio-Oncology

a section of the journal

Frontiers in Cardiovascular Medicine

Received: 12 August 2021 Accepted: 17 December 2021 Published: 13 January 2022

Citation:

Norton N, Bruno KA, Di Florio DN, Whelan ER, Hill AR, Morales-Lara AC, Mease AA, Sousou JM, Malavet JA,

Dorn LE, Salomon GR, Macomb LP Khatib S, Anastasiadis ZP, Necela BM,

McGuire MM, Giresi PG, Kotha A, Beetler DJ, Weil RM, Landolfo CK and Fairweather D (2022) Trpc6 Promotes Doxorubicin-Induced Cardiomyopathy in Male Mice With Pleiotropic Differences Between Males and Females

Front. Cardiovasc. Med. 8:757784. doi: 10.3389/fcrm.2021.757784
Nadine Norton ${ }^{1 * \neq}$, Katelyn A. Bruno ${ }^{2,3 \dagger}$, Damian N. Di Florio ${ }^{2,3}$, Emily R. Whelan ${ }^{2}$, Anneliese R. Hill ${ }^{2}$, Andrea Carolina Morales-Lara ${ }^{2}$, Anna A. Mease ${ }^{2}$, John M. Sousou ${ }^{2}$, Jose A. Malavet ${ }^{2}$, Lauren E. Dorn ${ }^{2}$, Gary R. Salomon ${ }^{2}$, Logan P. Macomb ${ }^{2}$, Sami Khatib ${ }^{2}$, Zacharias P. Anastasiadis ${ }^{1}$, Brian M. Necela ${ }^{1}$, Molly M. McGuire ${ }^{2}$, Presley G. Giresi ${ }^{2}$, Archana Kotha ${ }^{2,3}$, Danielle J. Beetler ${ }^{2,3}$, Raegan M. Weil ${ }^{1}$, Carolyn K. Landolfo ${ }^{2}$ and DeLisa Fairweather ${ }^{2,3 * \neq}$

${ }^{1}$ Department of Cancer Biology, Mayo Clinic, Jacksonville, FL, United States, ${ }^{2}$ Department of Cardiovascular Medicine, Mayo Clinic, Jacksonville, FL, United States, ${ }^{3}$ Center of Clinical and Translational Science, Mayo Clinic, Jacksonville, FL, United States

Background: Doxorubicin is a widely used and effective chemotherapy, but the major limiting side effect is cardiomyopathy which in some patients leads to congestive heart failure. Genetic variants in TRPC6 have been associated with the development of doxorubicin-induced cardiotoxicity, suggesting that TRPC6 may be a therapeutic target for cardioprotection in cancer patients.

Methods: Assessment of Trpc6 deficiency to prevent doxorubicin-induced cardiac damage and function was conducted in male and female B6.129 and Trpc6 knock-out mice. Mice were treated with doxorubicin intraperitoneally every other day for a total of 6 injections (4 mg/kg/dose, cumulative dose $24 \mathrm{mg} / \mathrm{kg}$ ). Cardiac damage was measured in heart sections by quantification of vacuolation and fibrosis, and in heart tissue by gene expression of Tnni3 and Myh7. Cardiac function was determined by echocardiography.

Results: When treated with doxorubicin, male Trpc6-deficient mice showed improvement in markers of cardiac damage with significantly reduced vacuolation, fibrosis and Myh7 expression and increased Tnni3 expression in the heart compared to wild-type controls. Similarly, male Trpc6-deficient mice treated with doxorubicin had improved LVEF, fractional shortening, cardiac output and stroke volume. Female mice were less susceptible to doxorubicin-induced cardiac damage and functional changes than males, but Trpc6-deficient females had improved vacuolation with doxorubicin treatment. Sex differences were observed in wild-type and Trpc6-deficient mice in body-weight and expression of Trpc1, Trpc3 and Rcan1 in response to doxorubicin.

Conclusions: Trpc6 promotes cardiac damage following treatment with doxorubicin resulting in cardiomyopathy in male mice. Female mice are less susceptible to cardiotoxicity with more robust ability to modulate other Trpc channels and Rcan1 expression.

Keywords: cardiotoxicity, anthracycline, heart failure, sex differences, ion channel, TRPC 


\section{INTRODUCTION}

Doxorubicin is a widely used and effective chemotherapy agent for multiple adult and pediatric cancers. However, a potential side effect is cumulative, dose-related, progressive myocardial damage that can lead to congestive heart failure (CHF), even several years after completion of treatment (1-6). The mechanisms of cardiotoxicity leading to cardiomyopathy are likely complex including generation of reactive oxygen species (ROS) and iron (7), doxorubicin binding to topoisomerases (8), impaired mitochondrial function (9), disruption of calcium homeostasis (10-12), up-regulation of death receptors (13), and up-regulation of the potent vasoconstrictor endothelin 1 which causes fibrosis and the generation of ROS (14).

ASCO guidelines for monitoring and preventing cardiac dysfunction after doxorubicin therapy state that currently there is not sufficient evidence to recommend any single heart failure medication such as angiotensin-converting enzyme (ACE) inhibitors or beta blockers to improve function (15). To date, the only FDA-approved cardioprotective drug for doxorubicin-induced cardiomyopathy is the iron chelating agent, Dexrazoxane, which is thought to deplete topoisomerase IIb (16, 17) and prevent mitochondrial iron-catalyzed ROS damage (7). However, for a therapy to be useful in mediating cardioprotection it is important that it does not counteract the anti-tumor effect of the chemotherapy agent, and there are concerns that Dexrazoxane may interfere with the antitumor efficacy of doxorubicin (18). To date, alternative iron chelators have yielded negative or mixed outcomes (7) indicating that there is a need to find alternative strategies for cardioprotection from anthracyclines.

Given the multiple, complex mechanisms of doxorubicininduced cardiotoxicity and the variability in patient cardiovascular outcome, we previously used a genomewide approach to identify genetic variants that were associated with doxorubicin-induced decline in left ventricular ejection fraction (LVEF) (19). That study identified transient receptor potential cation channel subunit 6 (TRPC6) as a potential risk locus for doxorubicin-induced cardiomyopathy in patients with breast cancer (19). In a follow-up study from our group using 984 patients from the Mayo Clinic Biobank, we replicated the association of toxicity, specifically with the outcome of doxorubicin-induced congestive heart failure (CHF) (20).

TRPC1-7 channels are an important group of calcium permeable ion channels that induce changes in cardiac function in response to cardiac strain and/or disease (21). Different missense mutations in TRPC6 have been shown to result in excess calcium influx, largely by gain-of-function mutations (22), leading to the hypothesis that individuals carrying TRPC6 variants could be at increased risk of doxorubicin-induced cardiotoxicity and cardiomyopathy and perhaps be candidates

\footnotetext{
Abbreviations: CHF, congestive heart failure; ROS, reactive oxygen species; LVEF, left ventricular ejection fraction; TRPC6, transient receptor potential cation channel subunit 6; CHF, congestive heart failure; WT, wild-type; KO, knock-out; ip, intraperitoneally; qPCR, quantitative reverse transcriptase-mediated real-time PCR; (qRT)-PCR, quantitative real time; pi, post inoculation.
}

for TRPC inhibition as a cardioprotective strategy. A number of studies have demonstrated the potential of TRPC1, 3 and/or 6 channels as therapeutic targets for heart failure, predominantly using in vivo models of pressure overload in male mice (23-25). We previously published that pre-treatment of male mice with a TRPC6 inhibitor GsMTx-4 significantly reduced fibrosis and improved LVEF and cardiac strain in mice given doxorubicin (20). In this study, we hypothesized that genetic deficiency of Trpc6 would decrease cardiotoxicity and cardiomyopathy in male and female mice given doxorubicin.

\section{MATERIALS AND METHODS}

\section{Chemotherapy Agent}

Doxorubicin was purchased from Selleckchem (Houston, TX) in powder form $(25 \mathrm{mg})$ and dissolved in sterile water as $1.25 \mathrm{~mL}$ aliquots to a concentration of $20 \mathrm{mg} / \mathrm{mL}$ and stored at $4{ }^{\circ} \mathrm{C}$. For injections, the $20 \mathrm{mg} / \mathrm{mL}$ stock solution was diluted in sterile saline to a final concentration of $1 \mathrm{mg} / \mathrm{mL}$.

\section{Animal Model}

Animal protocols were performed according to NIH guidelines with approval from the Institutional Animal Care and Use Committee, Environmental Health and Occupational Safety Committee and the Biosafety Committee at Mayo Clinic. Mice were bred and maintained under pathogen-free conditions in the animal facility at the Mayo Clinic, fed standard chow and water ad libitum, and housed in animal rooms where the temperature was monitored. Breeding pairs of B6.129 wild-type (WT) (Cat\#101045) and B6.129 Trpc6 whole body knock-out (KO) mice (26) (Cat\#37345) were obtained from the Jackson Laboratory (Bar Harbor, ME). Male and female WT and Trpc6 KO mice (8-10 weeks old), ten mice per group, received either $100 \mu \mathrm{L}$ intraperitoneally (ip) of control sterile saline or 4 $\mathrm{mg} / \mathrm{kg} /$ dose doxorubicin for a cumulative dose of $24 \mathrm{mg} / \mathrm{kg}$ on days $1,3,5,7,9,11$ according to (20). Results were confirmed by repeating each experiment. Hearts were evaluated for cardiac function using echocardiography and tissues collected on day 14 and 21 .

\section{Echocardiography}

Cardiac function was performed by transthoracic echocardiogram using a Visual Sonic Vevo 2100 with a 55megahertz (MHz) transducer (Bothell, WA). Echocardiography was performed on living male and female animals under isoflurane inhalation at day 14 and 21 as per our previous publications $(20,27-30)$.

\section{Histology}

Mouse hearts were cut longitudinally, fixed in 10\% phosphatebuffered formalin, and embedded in paraffin for histological analysis. Five-micron-thick sections were stained with hematoxylin and eosin to detect vacuolation or trichrome blue to detect fibrosis. Vacuolation and fibrosis were calculated as the number of grids with vacuoles or fibrosis, respectively, compared to the total number of grids in the heart section using an eyepiece grid with a $2 \mathrm{x}$ objective lens (20x magnification) and 
converted to a percentage, as previously $(31,32)$. Sections were scored by two individuals blinded to experimental group.

\section{RNA Extraction}

At harvest, half of the heart was collected and stored at $-80^{\circ} \mathrm{C}$ for RNA isolation. Hearts were homogenized and lysed using Tissuelyser (Qiagen) with $7 \mathrm{~mm}$ stainless steel beads in RTL buffer with $0.5 \%$ DX buffer to reduce foam (Hilden, Germany). The homogenate was then placed in an automated RNA isolation and purification instrument, QIAcube, with reagents for RNase Easy Fibrous Mini Kit including a DNase and Proteinase K step (Qiagen \#74704). RNA was eluted into $30 \mu \mathrm{L}$. If the heart had been divided in the earlier step, the eluted RNA was pooled prior to being aliquoted. RNA quantification was determined in $\mu \mathrm{g} / \mu \mathrm{L}$ using NanoDrop (Thermo Scientific, Waltham, MA).

\section{Quantitative PCR}

Two-step quantitative reverse transcriptase-mediated real-time PCR (qPCR) was used to measure abundance of individual mRNAs. Total RNA from mouse hearts was assessed by quantitative real time (qRT)-PCR using Assay-on-Demand primers and probe sets and the ABI 7000 Taqman System from Applied Biosystems (Foster City, CA) after RNA was converted to cDNA using a High Capacity cDNA Reverse Transcriptase Kit (Applied Biosystems), and qPCR reactions were performed in triplicate with $100 \mathrm{ng}$ of cDNA and the TaqMan Universal PCR master mix (Applied Biosystems), as previously described $(28,29)$. The following primer/probe sets were purchased from Applied Biosystems: Trpc1 (Mm00441975_m1), Trpc3 (Mm00444690_m1), Trpc6 (Mm01176083_m1), Myh7 (Mm00600555_m1), Tnni3 (Mm00437164_m1) and Rcan1 (Mm01213406_m1). Amplification data were collected with an Applied Biosystems ViiA7 detector and analyzed with ViiA7 v 1.2.4 software (Life Technologies). Data were normalized to the endogenous control Polr2a (Mm00839502_m1) (33) and mRNA abundance was calculated using the $\Delta \Delta \mathrm{CT}$ method and displayed as fold change (FC) (34).

\section{TUNEL Assay}

Hearts were fixed in $10 \%$ buffered formalin for $48 \mathrm{~h}$ and transferred to containers of PBS prior to paraffin embedding and mounting on slides. TUNEL Assay was performed using the Click-iT Plus TUNEL Assay for in situ Apoptosis Detection on the Alexa 647 (ThermoFisher, Cat: C10619). Slides were deparaffinized per manufacturer recommendations and steamed for 30 min prior to permeabilizing with Proteinase K. Tissue autofluorescence was quenched with Vector TrueVIEW Autofluorescence Quenching Kit (Vector Laboratories, Cat: SP8400-15). Heart sections were incubated with TdT Reaction Buffer for $20 \mathrm{~min}$ at $37^{\circ} \mathrm{C}$ prior to performing the $\mathrm{TdT}$ Reaction for $60 \mathrm{~min}$ at $37^{\circ} \mathrm{C}$. TUNEL reaction was performed for $45 \mathrm{~min}$ at $37^{\circ} \mathrm{C}$. Nuclei were counter-stained with Hoechst 33342 (ThermoFisher, Cat: H21492) and then mounted with Vectashield Antifade Mounting Medium (Vector Labs, Cat: H1000-10). After drying for $48 \mathrm{~h}$, slides were scanned with a Panoramic 250 fluorescent slide scanner (3DHISTECH). The ventricles of heart sections were selected and annotated in

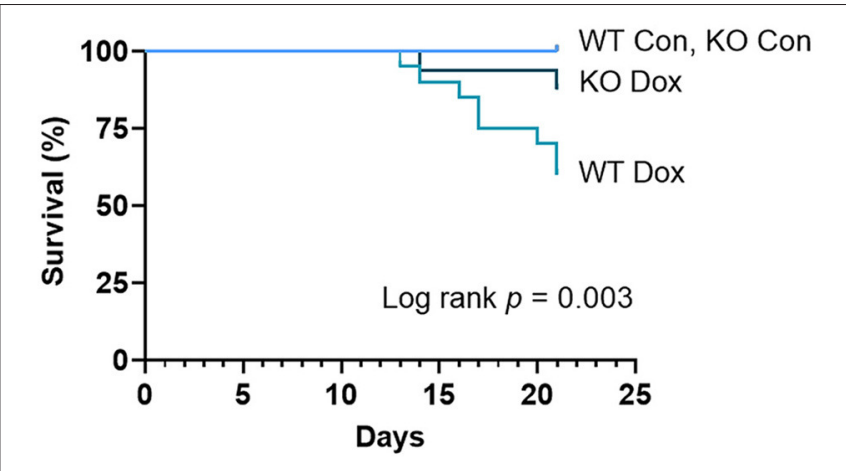

FIGURE 1 | Trpc6 deficiency improves survival in male mice treated with doxorubicin. Male wild-type (WT) and Trpc6-deficient (KO) mice were treated with $100 \mathrm{~mL}$ saline (CON) or $4 \mathrm{mg} / \mathrm{kg}$ doxorubicin (DOX) on days 1, 3, 5, 7, 9, 11 for a cumulative dose of $24 \mathrm{mg} / \mathrm{kg}$. Two separate experiments of 10 mice/group were combined ( $n=20 /$ group) and analyzed by log-rank (Mantel-Cox) test.

CaseViewer (3DHISTECH). TUNEL positivity was determined in QuantCenter (3DHISTECH) using cell quant with the following parameters: Channel Matching - default; Detection - nuclei selected for both the DAPI and Cy5 channels; Nuclei - contrast set to 35, other settings were default; Cytoplasm - n/a; Membrane - n/a; Scoring - object selected was nuclei and channel selected was Cy5. These parameters allowed for identification of all nuclei and then determination of the frequency of TUNEL/Cy5 positivity where the aggregate score of Medium and Strong Positive Nuclei $=$ TUNEL positive.

\section{Statistical Analysis}

Statistical analyses were performed in GraphPad Prism 9.0.1. Differences between two groups were tested by unpaired 2tailed Student's $t$-test. Differences between more than two groups were tested by one-way ANOVA followed by Tukey's or HolmSidak's multiple comparison tests. Differences between groups over time were compared by two-way ANOVA. Survival curves were analyzed by log-rank (Mantel-Cox) test. Data are expressed as mean \pm SEM. A value of $p<0.05$ was considered significant.

\section{RESULTS}

\section{Trpc6 Deficiency Improves Survival in Male Mice Following Doxorubicin Treatment}

Shortly after the accumulative dose of doxorubicin was achieved at day 11 post inoculation, male wild-type and Trpc6-deficient mice began to die, although the specific cause of death was not ascertained (Figure 1). Deficiency in Trpc6 improved survival after doxorubicin treatment in males, $(p=0.003$, Figure 1$)$. These findings suggest that Trpc6 contributes to mortality following doxorubicin therapy in male mice. 


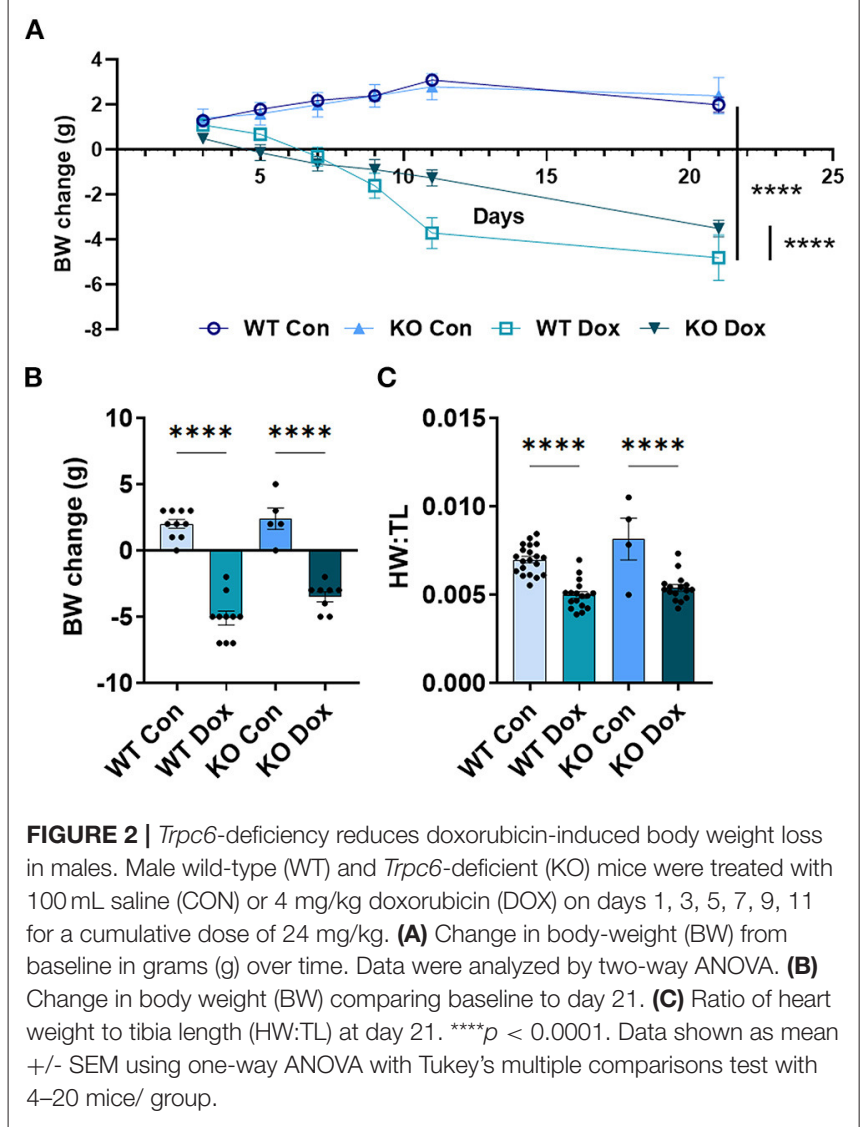

\section{Trpc6 Deficiency Improves Doxorubicin-Induced Body Weight Loss in Males}

Mice were weighed immediately prior to each injection of doxorubicin to ensure the correct dose was used (approximately $4 \mathrm{mg} / \mathrm{kg}$ per dose). As expected, both wild-type and Trpc6deficient males treated with doxorubicin progressively lost body-weight relative to control mice ( $p<0.0001$, Figure $2 \mathrm{~A}$ ), while wild-type and Trpc6-deficient control males maintained their weight over the duration of the experiment $(p=0.724$, Figure 2A). The loss in weight for wild-type and Trpc6-deficient mice treated with doxorubicin was observed at day 21 ( $p$ $<0.0001$, Figure 2B). However, Trpc6-deficient mice treated with doxorubicin lost less weight than wild-type mice treated with doxorubicin over the duration of the experiment $(p<$ 0.0001 , Figure 2A), suggesting that $\operatorname{Trpc} 6$ worsens the effects of doxorubicin.

In mice that survived to day 21 , we also determined the heart-weight to tibia length (HW:TL) ratio. An elevated HW:TL indicates cardiac hypertrophy. Instead, we found that doxorubicin treatment caused a reduction in HW:TL in wildtype and Trpc6-deficient males ( $p<0.001$, Figure $2 \mathrm{C}$ ), indicating cardiac damage, that was not recovered by $\operatorname{Trpc} 6$ deficiency ( $p=$ 0.64 , Figure 2C). Thus, Trpc6 contributes to loss of body weight due to doxorubicin treatment but does not alter heart weight in male mice.

\section{Trpc6 Deficiency Improves Cardiac Damage and Function at Day 21 in Male Mice Treated With Doxorubicin}

We next examined gene expression of two known biomarkers of heart damage, cardiac troponin (Tnni3) and myosin heavy chain 7 ( $M y h 7$, also known as myosin heavy chain beta), in male mice at day 21. Both Tnni3 and Myh7 gene expression was significantly different between groups by ANOVA $(p<0.0001$ and $p<$ 0.0001 , respectively, Figures 3A,B). Tnni3 expression in the heart of wild-type mice was significantly reduced by doxorubicin treatment compared to saline controls, $p<0.0001$, and the reduction was almost completely reversed by $\operatorname{Trpc} 6$ deficiency, $(p<0.0001$, Figure 3A), indicating that $\operatorname{Tr} p c 6$ promotes cardiac damage. Myh7 expression, which is known to increase in failing human $(35,36)$ and mouse hearts $(37,38)$, increased significantly in male wild-type mice treated with doxorubicin, $p<0.0001$, and was also reversed by $\operatorname{Trpc6}$ deficiency, $(p<0.0001$, Figure 3B), indicating that Trpc6 promotes cardiac damage. The gene expression levels of Tnni3 and $M y h 7$ were very similar between wild-type and Trpc6-deficient saline control males indicating that there was no apparent underlying difference in cardiac damage between the two mouse strains. Together, these data show that Trpc6 worsens cardiac damage in response to doxorubicin.

TUNEL Assay was performed to determine whether cardiac apoptosis was present 21 days after treatment with doxorubicin. We did not observe significant changes in apoptosis at day 21 after doxorubicin exposure between groups (Figure 3C). Fibrosis was found to be present in the heart at day 21 (Figure 4) and apoptosis is a process that primarily occurs prior to remodeling and fibrosis.

Vacuolation, a known effect of doxorubicin-induced cardiac damage in humans, was observed in male mice treated with doxorubicin $(p<0.0001$, Figures 3D-H). Trpc6-deficiency significantly reduced cardiac vacuolation compared to wild-type controls following treatment with doxorubicin $(p<0.0001$, Figures 3D-H), further demonstrating that Trpc6 promotes cardiac damage following doxorubicin treatment.

Cardiac fibrosis is well known to cause cardiomyopathy/dilated cardiomyopathy that can be detected by echocardiography in conditions such as viral myocarditis $(31,32)$. Cardiac fibrosis was assessed at day 21 . Wild-type mice treated with doxorubicin showed a significant increase in fibrosis in the heart $(p=0.010$, Figure 4A) while Trpc6-deficiency significantly decreased fibrosis ( $p=0.028$, Figure 4A).

Cardiac function was measured in male mice at day 14 and 21 by echocardiography (Figure 4). No significant changes were observed for any group at day 14 (data not shown). At day 21, wild-type mice treated with doxorubicin showed a significant decrease in heart rate, $(p=0.029$, Figure 4B), LVEF, $(p=$ 0.042 , Figure $4 C)$, fractional shortening, $(p=0.037$, Figure $4 \mathrm{D})$, cardiac output, $(p<0.0001$, Figure $4 \mathrm{E})$ and stroke volume, $(p=$ 0.0001 , Figure 4F) compared to wild-type control males. Trpc6deficiency significantly improved cardiac function compared to 


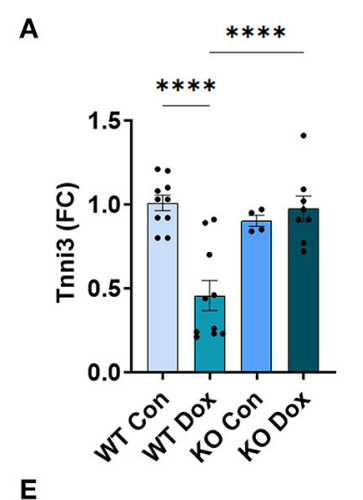

B

C D
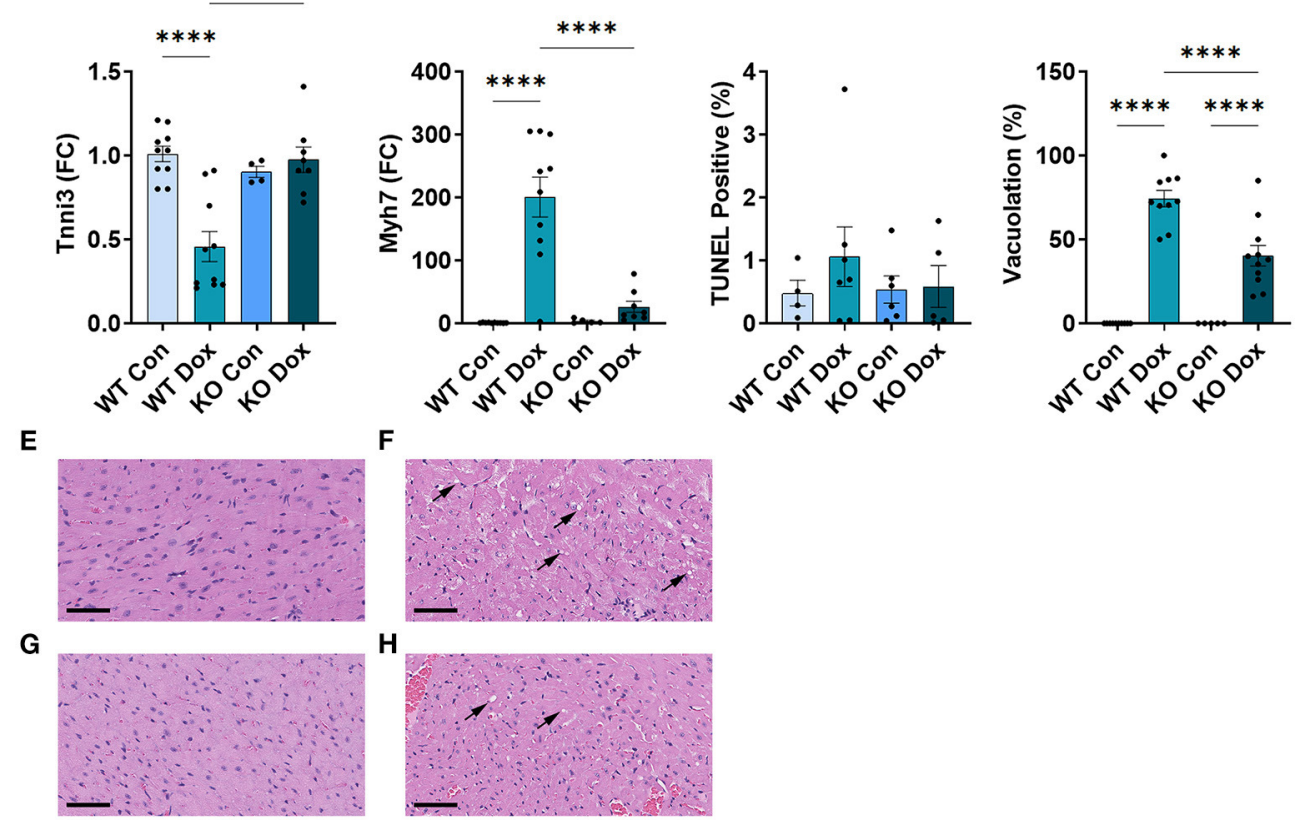

FIGURE 3 | Trpc6-deficiency reduces cardiac damage following doxorubicin in males. Male wild-type (WT) and Trpc6-deficient (KO) mice were treated with 100 mL saline (CON) or $4 \mathrm{mg} / \mathrm{kg}$ doxorubicin (DOX) on days 1, 3, 5, 7, 9, 11 for a cumulative dose of 24 mg/kg. (A) Cardiac troponin (Tnni3) or (B) myosin heavy chain 7 (Myh7) gene expression shown as a fold change (FC) relative to WT Control. (C) TUNEL Positive (\%). (D) Percent vacuolation. ${ }^{\star \star \star \star} p<0.0001$. Data shown as mean +/- SEM using one-way ANOVA with Tukey's multiple comparisons test with 4-10 mice/ group. Hematoxylin and eosin (H\&E) staining of representative heart sections from (E) male wild-type (WT) mice treated with saline (Con), (F) male wild-type (WT) mice treated with doxorubicin (Dox), (G) Trpc6-deficient (KO) mice treated with saline, or (H) Trpc6-deficient (KO) mice treated with Dox showing vacuoles in black arrows. Magnification 400x. Scale bars are 60 $\mu \mathrm{m}$.

wild-type males treated with doxorubicin for heart rate $p=$ 0.022 , LVEF $p=0.048$, fractional shortening $p=0.043$, cardiac output $p=0.002$, and stroke volume $p=0.048$, respectively (Figures 4B-F). Measures of left ventricular end diastolic and left ventricular end systolic diameters (LVEDD, LVESD) used to determine cardiac dilatation showed that neither doxorubicin nor Trpc6 deficiency led to dilated cardiomyopathy at this time point in males (Figures $\mathbf{4 G}, \mathbf{H}$ ). Thus, these data indicate that Trpc6 promotes cardiac damage that leads to cardiomyopathy following doxorubicin treatment in males.

\section{In Male Mice, Trpc6 Deficiency Improved Trpc-Related Gene Expression in the Heart Following Treatment With Doxorubicin}

The TRPC family of proteins (TRPC1-7) function as both homoand hetero-tetramers, and both $\operatorname{Trpc1}$ and $\operatorname{Trpc} 3$ as well as Trpc6 have been implicated in heart failure induced by pressure overload $(23-25,39)$. Another study reported that Trpc6 is a positive regulator of calcineurin-NFAT signaling through the regulator of calcineurin (Rcan1) (40). Therefore, we sought to characterize the changes in cardiac gene expression of Trpc6 in response to doxorubicin and Trpc1, 3 and Rcan1 in Trpc6deficient mice after doxorubicin treatment.

In the hearts of male wild-type mice, we observed decreases in Trpc6, $\operatorname{Trpc1}$ and $\operatorname{Trpc3}$ gene expression in response to doxorubicin compared to saline controls, $p=0.0087, p=0.032$ and $p<0.0001$, respectively (Figures 5A-C), but no significant change was observed in the expression of Rcan1 (Figure 5D). In Trpc6 deficient mice, the doxorubicin-induced changes in expression of $\operatorname{Tr} p c 1$ and $\operatorname{Trcp} 3$ were reversed (Figures 5B,C). However, the expression of $\operatorname{Trpc} 3$ in the hearts of $\operatorname{Trpc} 6$ deficient control mice was significantly lower than that of wild-type control mice, ( $p=0.004$, Figure 5C), indicating that Trpc6-deficiency alters cardiac Trpc3 expression regardless of doxorubicin treatment.

\section{Female Mice Are Less Susceptible to Doxorubicin-Induced Cardiac Damage, Cardiomyopathy and Death Compared to Males}

Given that women with breast cancer are commonly treated with doxorubicin and that our initial genetic studies identified TRPC6 genetic variants as associated with a decline in LVEF in women with breast cancer (19), in this study we also assessed female mice treated with the same dose of doxorubicin as the dose given to males. In female wild-type mice, all wild-type and Trpc6-deficient mice survived treatment with doxorubicin (data not shown). In contrast to males, only Trpc6-deficient female mice treated with doxorubicin lost body weight over the duration of the experiment (Figure 6A). At day 21 (Figure 6B) wild-type female mice treated with doxorubicin maintained their weight, and no changes were observed in HW:TL in females for any group (Figure 6C). 
A
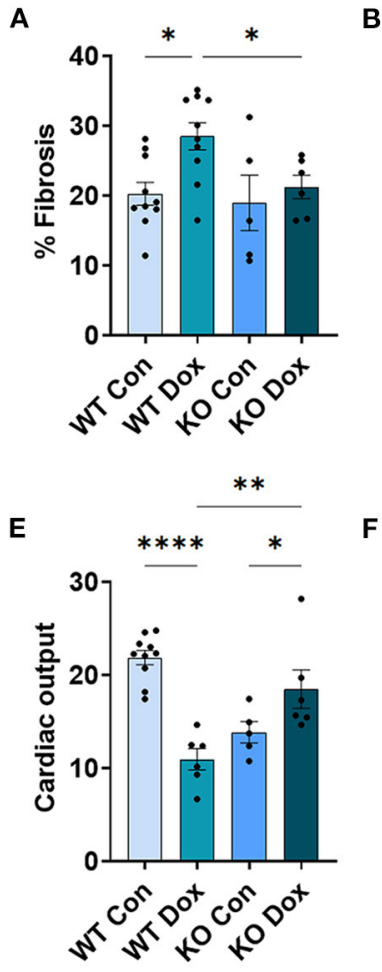

B

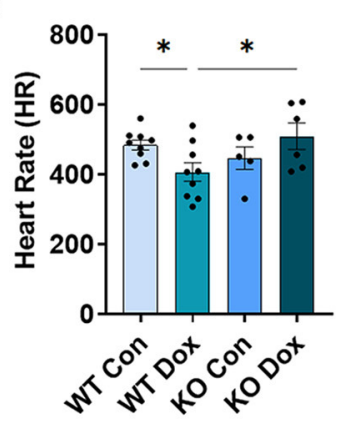

$\mathbf{F}$

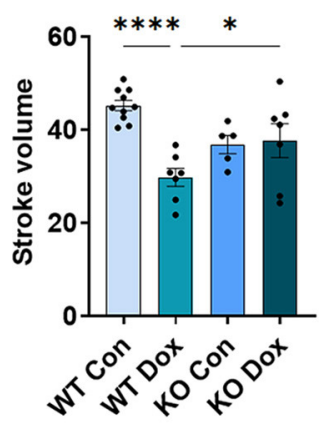

C

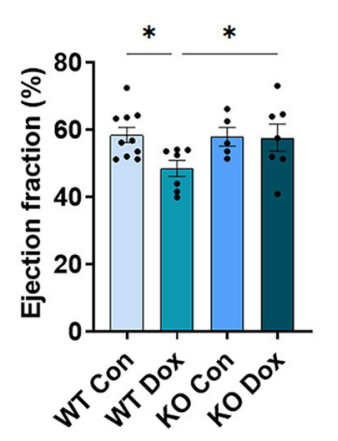

G

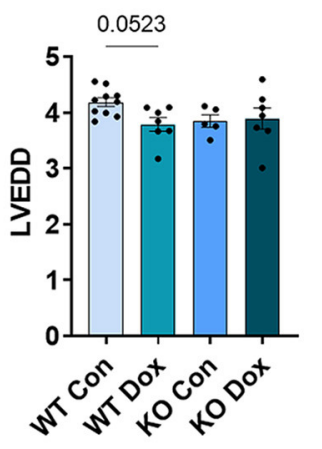

D

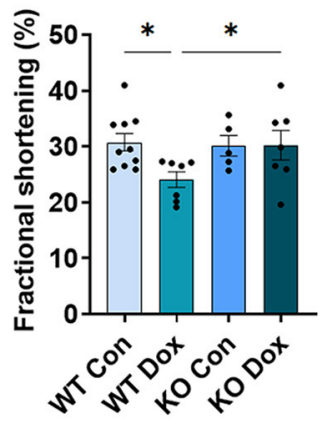

H

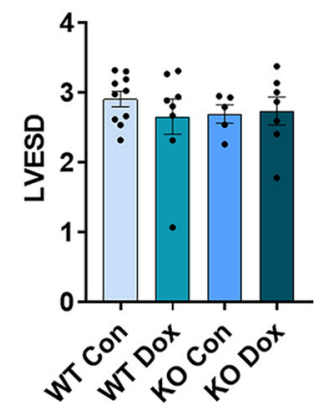

FIGURE 4 | Trpc6-deficiency improves cardiac function assessed using echocardiography in males treated with doxorubicin. Male wild-type (WT) and Trpc6-deficient (KO) mice were treated with $100 \mathrm{~mL}$ saline (CON) or $4 \mathrm{mg} / \mathrm{kg}$ doxorubicin (DOX) on days 1, 3, 5, 7, 9, 11 for a cumulative dose of $24 \mathrm{mg} / \mathrm{kg}$. Trichrome blue staining was performed at day 21 to assess (A) \% fibrosis. Echocardiogram was performed at day 21 to assess (B) heart rate (HR), (C) \% left ventricular (LV) ejection fraction, (D) \% fractional shortening, (E) cardiac output, (F) stroke volume, (G) LV end diastolic diameter (LVEDD) or (H) LV end systolic diameter (LVESD). ${ }^{\star} p<0.05,{ }^{\star \star} p<$ 0.01, ${ }^{\star \star \star *} p<0.0001$. Data shown as mean +/- SEM using one-way ANOVA with Holm-Šídák's multiple comparisons test with 5-10 mice/ group.

As observed in male mice, Tnni3 cardiac gene expression was significantly reduced in wild-type females treated with doxorubicin ( $p=0.050$, Figure 7A), but unlike males, gene expression of $M y h 7$ in wild-type females was not significantly altered by doxorubicin, $(p>0.999$, Figure 7B). Similar to males, female mice developed vacuolation following treatment with doxorubicin, ( $p<0.0001$, Figure 7D) that was less severe than males (mean vacuolation in wild-type females treated with doxorubicin $=18.24 \%$ vs. $74.44 \%$ in males) (Figure $7 D$ ). And as with males, $\operatorname{Tr} p c 6$-deficiency significantly reduced vacuolation in females treated with doxorubicin ( $p=0.049$, Figure 7D). Finally, we did not observe any significant change in cardiac fibrosis or echocardiographic parameters in female mice at day 21 in response to doxorubicin or Trpc6-deficiency (Figure 8). Thus, cardiac damage caused by doxorubicin was far less in females and did not lead to cardiomyopathy at day 21 .

\section{Pleiotropic Effects of Trpc6 Deficiency in Female Mice Following Doxorubicin Treatment}

Although female wild-type and Trpc6-deficient mice were less susceptible to doxorubicin-induced cardiac damage and cardiomyopathy, we did observe other significant effects of Trpc6 deficiency in female mice compared to males.

In contrast to males (Figure 2A), female wild-type mice treated with doxorubicin did not lose weight (Figure 6A). The reason for this is not clear. Rather than wild-type mice being worse in males, $\operatorname{Trpc} 6$-deficient females treated with doxorubicin had a greater loss in body weight over time and at day 21 compared to wild-type mice treated with doxorubicin $(p<0.0001$, Figures 6A,B). Although doxorubicin significantly decreased HW:TL (caused heart damage) in males (Figure 2C), there was no change in heart weight (no cardiac damage) in females (Figure 6C).

In contrast to males (Figure 3A), Tnni3 cardiac gene expression was significantly lower in Trpc6-deficient compared to wild-type saline control females ( $p<0.0001$, Figure 7A). In contrast to males, Tnni3 gene expression was significantly decreased in control and doxorubicin treated Trpc6-deficient females (Figure 7A), suggesting that Trpc6 deficiency altered Tnni3 levels in females. Pleiotropic effects of Trpc6 deficiency in response to doxorubicin were also observed for $M y h 7$ gene expression in the hearts of female (Figure 7B) vs. male (Figure 3B) mice. In female mice, $M y h 7$ levels remained low in all groups except for Trpc6-deficient mice treated with 


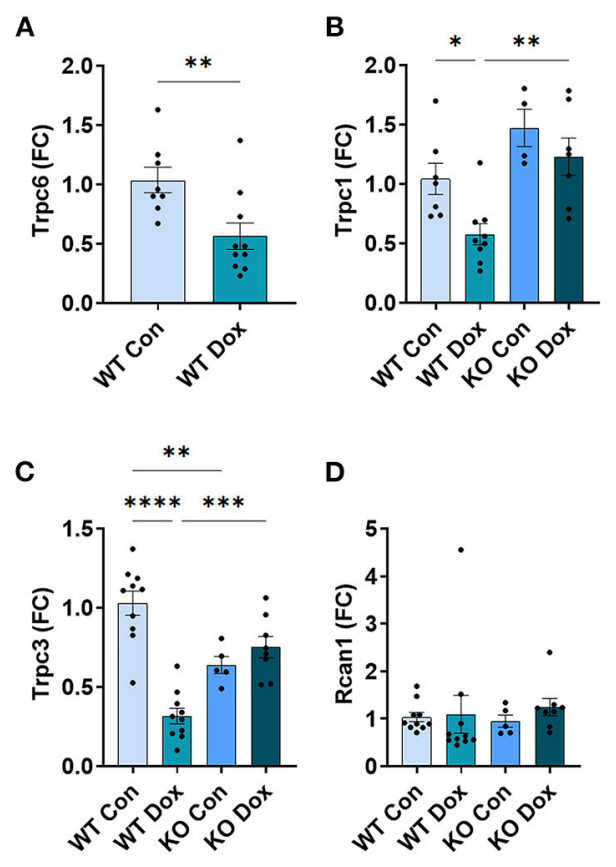

FIGURE 5 | Other Trpc gene expression is not altered in Trpc6-deficient males after doxorubicin treatment. Male wild-type (WT) and Trpc6-deficient (KO) mice were treated with $100 \mathrm{~mL}$ saline (CON) or $4 \mathrm{mg} / \mathrm{kg}$ doxorubicin (DOX) on days $1,3,5,7,9,11$ for a cumulative dose of $24 \mathrm{mg} / \mathrm{kg}$. Cardiac gene expression shown as a fold change (FC) relative to WT control for (A) Trpc6, (B) Trpc1, (C) Trpc3 or (D) Rcan1 at day 21. ${ }^{\star} p<0.05,{ }^{* \star} p<0.01,{ }^{* \star *} p<0.001,{ }^{* \star * *} p<$ 0.0001. (A) Data shown as mean \pm SEM using 2 tailed Student's $t$ test with 10 mice/ group. (B-D) Data shown as mean \pm SEM using one-way ANOVA with Tukey's multiple comparisons test with 4-10 mice/ group.

doxorubicin, where there was a significant increase relative to wild-type controls, $(p=0.049$, Figure 7B).

In the hearts of female wild-type mice, doxorubicin induced a significant reduction in Trpc6 gene expression compared to wildtype controls ( $p=0.039$, Figure 9A) similar to the decrease observed in male mice (Figure 5A), but did not induce changes in Trpc1, $\operatorname{Tr} p c 3$ or Rcan1 in wild-type mice (Figures 9B-D). A direct comparison of Trpc6 expression levels in the heart of male and female wild-type mice revealed that there were no significant differences in its expression before or after treatment with doxorubicin by sex (Figure 10). Interestingly, female Trpc6-deficient mice treated with saline had significantly lower expression of $\operatorname{Tr} p c 1,(p=0.002$, Figure 9B), $\operatorname{Tr} p c 3(p$ $<0.0001$, Figure 9C) and Rcan1 ( $p=0.009$, Figure 9D) than wild-type control mice. Thus overall, Trpc6 appears to increase cardiac damage in response to doxorubicin in females but not severely enough to lead to cardiomyopathy at the dose used in these experiments.

\section{DISCSUSSION}

In breast cancer patients, genetic variants at TRPC6 have been associated with doxorubicin-induced cardiomyopathy and congestive heart failure $(19,20)$. In vitro and in vivo, Trpc6

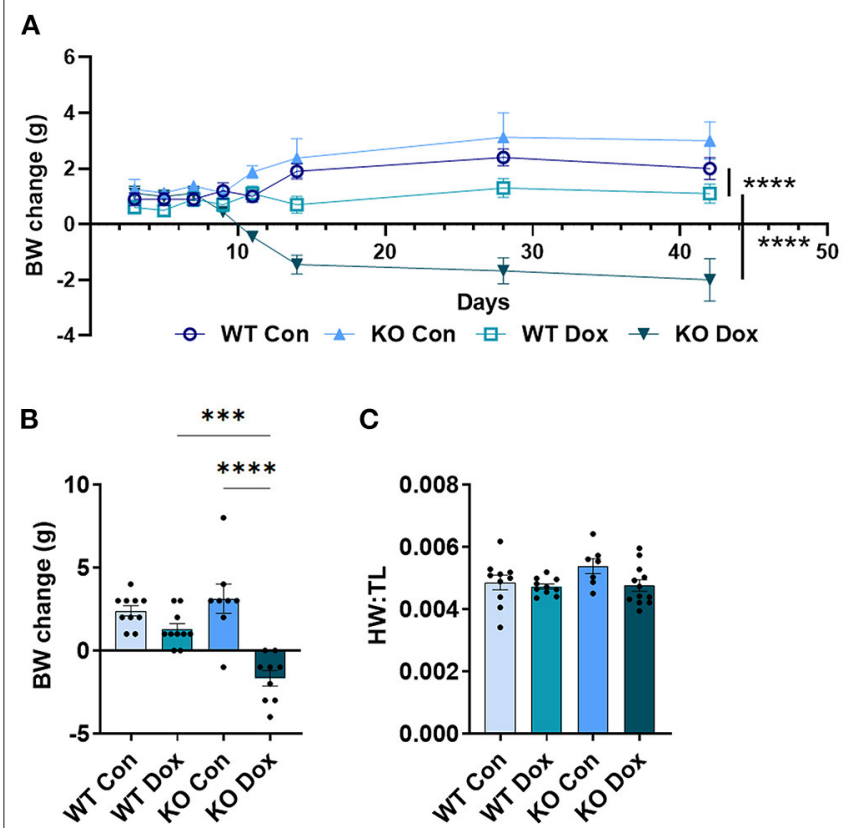

FIGURE 6 | Trpc6-deficienct females treated with doxorubicin lose body weight, with no effect on heart weight. Female wild-type (WT) and Trpc6-deficient $(\mathrm{KO})$ mice were treated with $100 \mathrm{~mL}$ saline $(\mathrm{CON})$ or $4 \mathrm{mg} / \mathrm{kg}$ doxorubicin (DOX) on days 1, 3, 5, 7, 9, 11 for a cumulative dose of $24 \mathrm{mg} / \mathrm{kg}$. (A) Change in body-weight (BW) from baseline in grams (g) over time. Data were analyzed by two-way ANOVA. (B) Change in body weight (BW) from baseline to day 21. (C) Ratio of heart weight to tibia length (HW:TL) at day 21. ${ }^{\star * *} p<0.001,{ }^{* \star * \star} p<0.0001$. Data shown as mean $+/$ - SEM using one-way ANOVA with Tukey's multiple comparisons test with 7-12 mice/ group.

inhibition with the peptide GsMTx4 reduced doxorubicininduced cardiotoxicity and cardiomyopathy in male mice (20). However, GsMTx4 also inhibits Piezo 1 and Piezo 2 (41) and TRPC1 (42) such that its cardioprotective effects could be mediated through mechanosensitive ion channels other than Trpc6 or the combination of multiple ion channels.

In this study, we specifically tested the role of Trpc6 in doxorubicin-induced cardiotoxicity and cardiomyopathy using male and female Trpc6 whole body knockout mice. In male mice in this study, we found that Trpc6 deficiency improved doxorubicin-induced cardiac damage (vacuolation, fibrosis, Tnni3 and Myh7) and cardiomyopathy indicating that Trpc6 promotes cardiac damage associated with doxorubicin therapy. To our knowledge, our study is the first to examine the effect of Trpc6 in doxorubicin-induced cardiomyopathy. Seo et al. (24) found that Trpc6 deficiency in male mice had no significant effect on hypertrophy induced using a pressure overload model by transverse aortic constriction (TAC). Improvement in hypertrophy following TAC required combined $\operatorname{Tr} p c 3$ and $\operatorname{Tr} p c 6$ deficiency (24). There are several reasons for differences between our study and Seo et al. Firstly, the genes and mechanisms involved in doxorubicin-induced heart failure are different than those in pressure overload models, and mice treated with doxorubicin in this study did not show signs of hypertrophic 
A

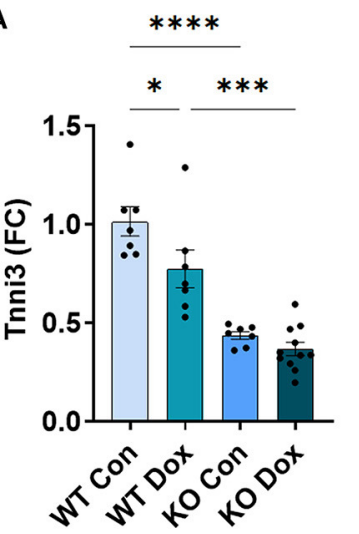

B

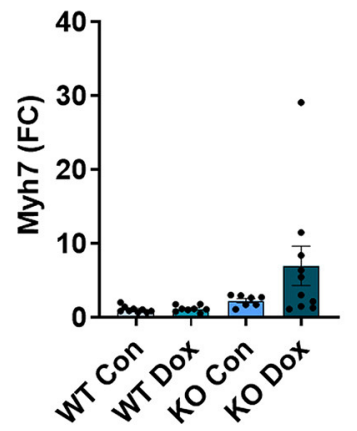

C

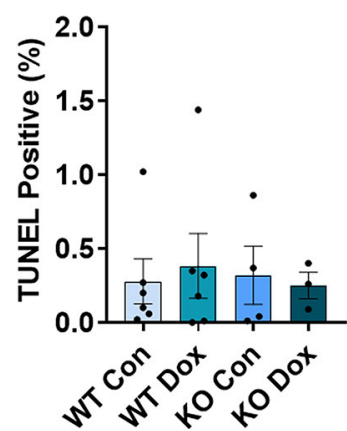

D

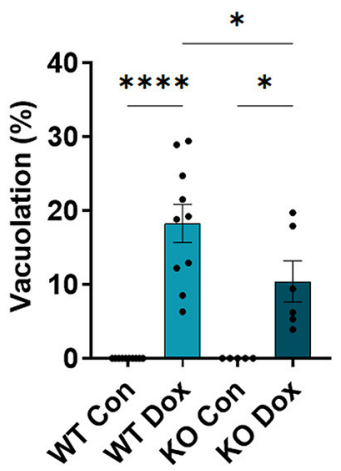

FIGURE 7 | Trpc6-deficiency reduces cardiac damage in females. Female wild-type (WT) and Trpc6-deficient (KO) mice were treated with $100 \mathrm{~mL}$ saline (CON) or 4 $\mathrm{mg} / \mathrm{kg}$ doxorubicin (DOX) on days 1, 3, 5, 7, 9, 11 for a cumulative dose of $24 \mathrm{mg} / \mathrm{kg}$. (A) Cardiac troponin (Tnni3) or (B) myosin heavy chain 7 (Myh7) gene expression shown as a fold change (FC) relative to WT control. (C) TUNEL Positive (\%) (D) Percent vacuolation. ${ }^{*} p<0.05,{ }^{* \star *} p<0.001,{ }^{* \star \star \star} p<0.0001$. Data shown as mean +/- SEM using one-way ANOVA with Tukey's multiple comparisons test with 4-12 mice/ group.
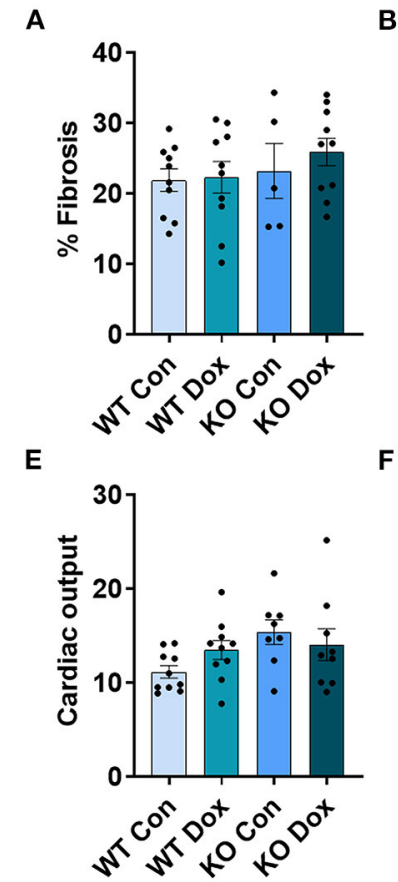
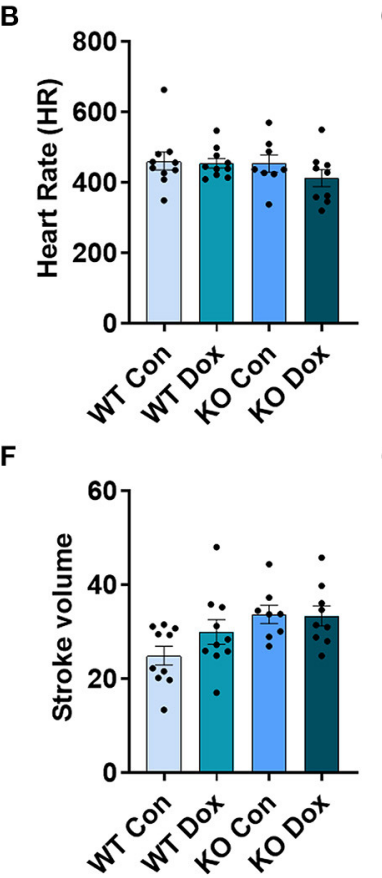

C
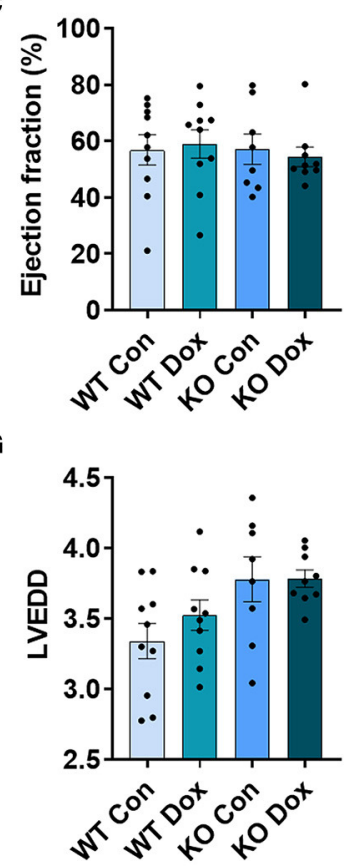

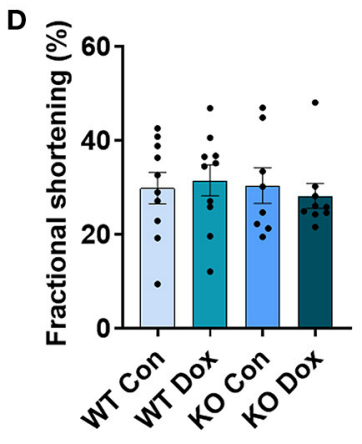

H

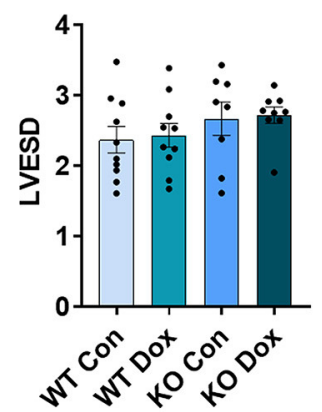

FIGURE 8 | In female mice, cardiac function measured by echocardiography was not impacted by doxorubicin or Trpc6 deficiency. Female wild-type (WT) and Trpc6-deficient (KO) mice were treated with $100 \mathrm{~mL}$ saline (CON) or 4 mg/kg doxorubicin (DOX) on days 1, 3, 5, 7, 9, 11 for a cumulative dose of 24 mg/kg. Trichrome blue staining was performed at day 21 to assess (A) \% fibrosis. Echocardiogram was performed at day 21 to assess (B) heart rate (HR), (C) \% left ventricular (LV) ejection fraction, (D) \% fractional shortening, (E) cardiac output, (F) stroke volume, (G) LV end diastolic diameter (LVEDD) or (H) LV end systolic diameter (LVESD). Data shown as mean \pm SEM using one-way ANOVA with Tukey's multiple comparisons with 5-10 mice/ group.

cardiomyopathy according to measurement of heart weight to tibia length. Secondly, some mouse strains are more sensitive to heart failure than others (both our study and Seo et al. used Trpc6 whole body knockout mice (26), but in the Seo study Trpc6 KO mice were backcrossed onto a C57BL/6J background and the mice in this study were on a B6.129 background).
Thirdly, it is possible that combined Trpc3 and Trpc6 deficiency could improve cardioprotection even further in mice treated with doxorubicin.

In the $\mathrm{KO}$ male and female mice in this study, we also observed that $\operatorname{Trp} 33$ expression was significantly lower in $\operatorname{Trpc} 6$ $\mathrm{KO}$ controls relative to wild-type controls raising the possibility 
A

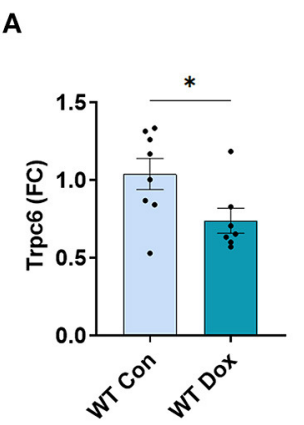

B

C

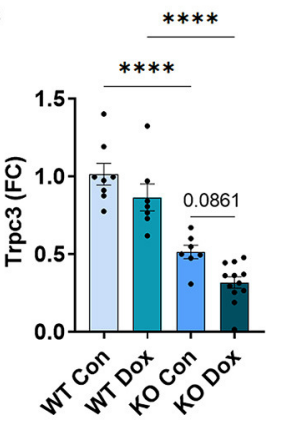

B

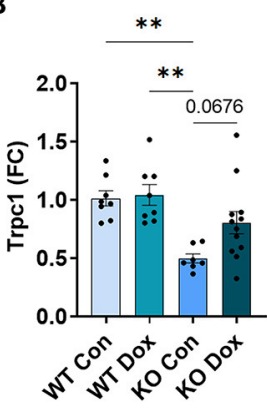

D

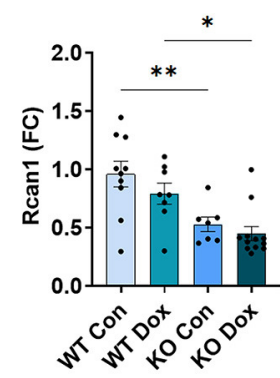

FIGURE 9 | Trpc6 expression is reduced by doxorubicin in female wild-type mice while Trpc1, Trpc3 and Rcan1 expression is reduced by Trpc6 deficiency. Female wild-type (WT) and Trpc6-deficient (KO) mice were treated with $100 \mathrm{~mL}$ saline (CON) or $4 \mathrm{mg} / \mathrm{kg}$ doxorubicin (DOX) on days 1, 3, 5, 7, 9, 11 for a cumulative dose of $24 \mathrm{mg} / \mathrm{kg}$. Cardiac gene expression shown as a fold change (FC) relative to WT control (A) Trpc6, (B) Trpc1, (C) Trpc3 and (D) Rcan1 at day 21. ${ }^{\star} p<0.05,{ }^{\star \star} p<0.01,{ }^{\star \star \star *} p<0.0001$. Data shown as mean \pm SEM using one-way ANOVA with Tukey's multiple comparisons with 7-12 mice/ group.

that at least some of the protective effect of Trpc6 deficiency could be mediated by decreased expression of $\operatorname{Trpc} 3$. Indeed, the work of others in pressure overload models of heart failure demonstrated that Pyr3- specific inhibition of $\operatorname{Trpc} 3$ attenuated pressure overload-induced heart failure in male mice (43), and the same group demonstrated that inhibition of the Trcp3-Nox2 complex suppressed doxorubicin-induced myocardial atrophy (44). However, an independent group demonstrated that both deletion and inhibition of Trpc6 reduced pressure overloadinduced fibrosis, but did not reduce pressure overload-induced cardiac dysfunction or ROS production (45), and a recent in vitro study found that doxorubicin-induced cell death was independent of TRPC6 channel up-regulation but involved mitochondrial activation of ROS (46). Taken together, our data and that of others suggest that cardioprotection through Trpc6 deficiency may be mediated by reduction of fibrosis (our previous work showed that doxorubicin-induced fibrosis was reduced in mice that were pre-treated with the Trpc6 inhibitor GsMTx4, which does not inhibit $\operatorname{Trpc} 3$ ) as well as by reduction in Trpc3 expression.

We are also the first study to our knowledge to examine whether sex differences exist in the effect of Trpc6 on cardiomyopathy following doxorubicin therapy. We found that

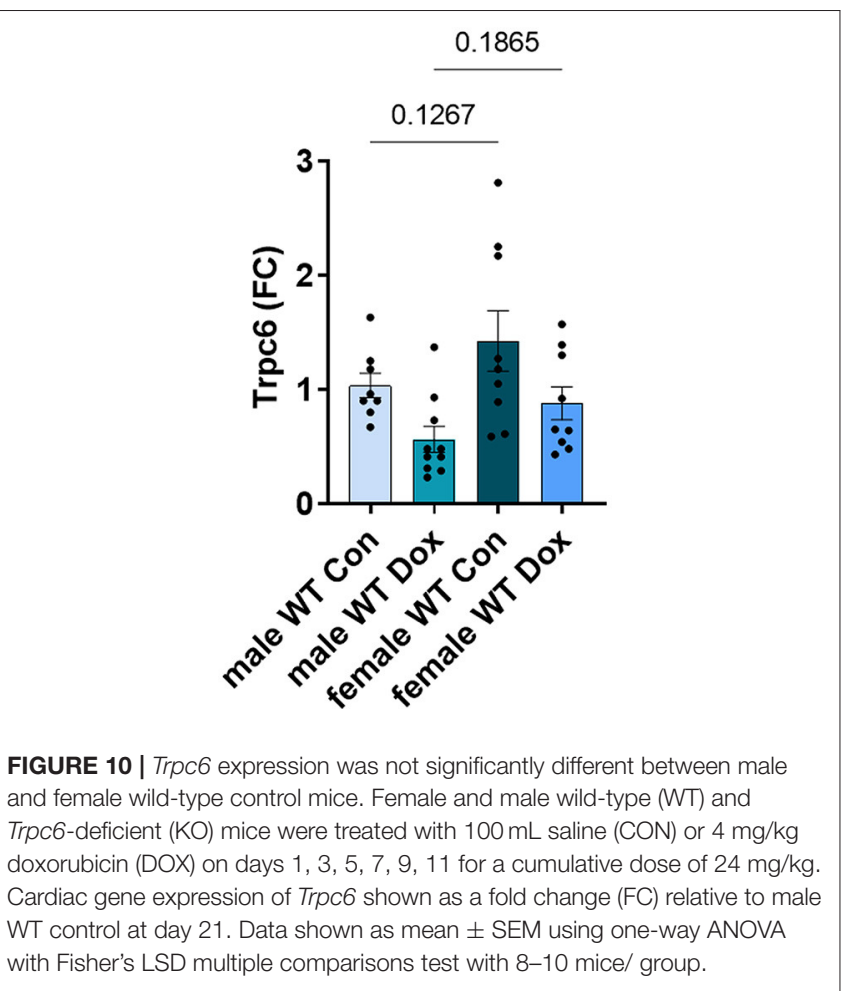

female B6.129 wild-type and Trpc6-deficient mice were far less susceptible to doxorubicin-induced cardiac damage and cardiomyopathy than males. This is consistent with the known sex differences in cardiomyopathy and heart failure where male mice and men develop worse cardiac function than females (47, 48). In animal models of heart disease, estrogen has been found to improve cardiac function in females $(30,49)$. Specifically, estrogen has been found to prevent cardiac hypertrophy by reducing calcineurin activity (50). Age also influences sex differences, with cardiovascular disease increasing in women after menopause and with increasing age (after 70 years of age) $(51,52)$. Additionally, older women (age $>65$ years, which accounts for $50 \%$ of breast cancer cases) are at higher risk of chemotherapy-related heart failure compared to younger women $(53,54)$ and the mice used in this study were 8 -10 week old young adults. Furthermore, other female rodent models have shown that ovariectomy is necessary for the development of heart failure (55). Future studies should examine whether ovariectomized female mice treated with doxorubicin develop more severe cardiac damage and cardiomyopathy.

In this study, we found that doxorubicin reduced Trpc6 gene expression in both male and female wild-type mice, suggesting a homeostatic response to buffer Trpc6-induced damage. We observed that $\operatorname{Trpc1}$ and $\operatorname{Trpc} 3$ expression were also significantly reduced in male wild-type mice in response to doxorubicin, but this did not occur in females. As female mice were much less susceptible to doxorubicin-induced cardiac damage, they may have greater ability to buffer Trpc6-induced changes in calcium levels. Sex hormones have been found to influence 
calcium channels $(56,57)$, and $17 \mathrm{~b}$-estradiol to upregulate canonical transient receptor potential channels (TRPC) in particular (58). This could explain the reduction in cardiac Trpc1, Trpc3 and Rcan1 gene expression in Trpc6-deficient saline control and doxorubicin-treated female mice that was not observed in males. Rcan 1 is involved in both development and maintenance of the cardiovascular system, and reduction in Rcan1 prevents pathological cardiac remodeling $(59,60)$. In this study, Rcan 1 expression was unchanged in male mice in response to doxorubicin or Trpc6-deficiency, but in Trpc6-deficient female mice, Rcan 1 expression was significantly reduced in females and the pattern of expression closely followed that of $\operatorname{Trpc} 3$ in each group of mice by treatment and Trpc6 status.

The observed sex differences in $\operatorname{Tr} p c$ channel expression in response to doxorubicin and Trpc6-deficiency suggest that estrogen is not only cardioprotective, but perhaps the mechanism of estrogen-related cardioprotection is mediated through TRPCrelated calcium signaling in the heart. Regulation of TRPC gene expression by estrogen was first reported in 1997 (61) and both $\mathrm{E}_{2}$ and the G-protein estrogen receptor (GPER) act to moderate calcium-activities in the cardiovascular system by lowering the peaks and raising the troughs, thus refining calcium levels to a more narrow and sustained operating range [reviewed in (62)]. Taken together, these data suggest that TRPC6 inhibition may serve as a potential cardioprotective therapy for male and post-menopausal female cancer patients that require doxorubicin.

Additionally, other work from our group identified genetic variants that were associated with both chemotherapy-induced heart failure and a decline in LVEF, and the same variants were also associated with increased TRPC6 expression in the heart, and in one case we identified a TRPC6 gainof-function variant in a 32 year old women with breast cancer who developed heart failure following doxorubicin and trastuzumab treatment (20) and (63) suggesting that TRPC6 inhibition may be particularly appropriate as a cardioprotection strategy for men and women who carry TRPC6 risk variants.

Our use of both female and male mice also demonstrated a significant interaction in female mice between doxorubicin and Trpc6 that may be clinically relevant to the management of patients receiving anthracyclines. The most striking sex difference was the loss of body-weight over time, in which male wild-type mice treated with doxorubicin lost a significant amount of body-weight whereas female wild-type mice were almost completely unaffected. In male mice, Trpc6-deficiency did not prevent doxorubicin-induced weight loss, but in female mice Trpc6-deficiency had a dramatic effect on weight gain in mice that received only saline control and a dramatic effect on weight loss in mice that were treated with doxorubicin, demonstrating genetic pleiotropy of $\operatorname{Trp} c 6$ deficiency in response to doxorubicin, specifically in female mice. These changes in body-weight appeared independent to changes in heart weight or cardiac function. However, we note that TRPC channels are often overexpressed in tumors, are a hallmark of metastasis (64) and in vitro, TRPC channel knock down or inhibition reduces tumor cell growth and migration $(65,66)$. Therefore, our observations of the pleiotropic effects of Trpc6-deficiency in female mice in relation to doxorubicin treatment may be of clinical relevance to the efficacy of doxorubicin in breast cancer patients. For example, would Trpc6 inhibition make breast tumors more sensitive to doxorubicin or prevent resistance to doxorubicin?

In summary, we demonstrated that Trpc6 deficiency alone is sufficient to protect male mice from doxorubicin-induced cardiac damage and decline in cardiac function, suggesting that TRPC6 may be a valuable therapeutic target for cancer patients who require doxorubicin. We further showed that wild-type female mice are less susceptible to doxorubicininduced damage, with low levels of cardiomyocyte vacuolation and no progression to cardiomyopathy at doses used in this study. Finally, we demonstrated significant sex differences in the gene expression of $\operatorname{Tr} p c 1, \operatorname{Tr} p c 3$ and Rcan1 in wild-type and Trpc6-deficient mice that may be due to the reciprocal relationship between estrogen and TRPC activity, which is of relevance to cardioprotection strategies for women with breast cancer.

\section{CONCLUSIONS}

Trpc6 induces cardiac damage and cardiomyopathy following treatment with doxorubicin in male mice and may be a therapeutic target for cardioprotection in patients. Female mice are less susceptible to cardiotoxicity but showed cardioprotection in Trpc6-deficient mice.

\section{DATA AVAILABILITY STATEMENT}

The original contributions presented in the study are included in the article/supplementary materials, further inquiries can be directed to the corresponding authors.

\section{ETHICS STATEMENT}

The animal study was reviewed and approved by Mayo Clinic, American Association for Laboratory Animal Science.

\section{AUTHOR CONTRIBUTIONS}

$\mathrm{NN}, \mathrm{KB}$, and $\mathrm{DF}$ designed the animal experiments. $\mathrm{KB}, \mathrm{DD}$, EW, AH, AM-L, AM, JS, JM, LD, GS, ZA, LM, SK, MM, PG, $\mathrm{AK}, \mathrm{DB}$, and $\mathrm{DF}$ performed animal experiments and animal maintenance. NN, KB, DD, EW, MM, AM-L, and AM performed doxorubicin dosing, weight tracking and collected survival data. $\mathrm{KB}, \mathrm{DD}, \mathrm{EW}$, and $\mathrm{AH}$ performed echocardiography. $\mathrm{KB}, \mathrm{DD}$, EW, JS, and CL analyzed echocardiography data. $\mathrm{KB}$ and SK performed tibia length measurements. KB, LM, and DF performed histological analysis. NN, KB, AH, JM, LD, GS, ZA, $\mathrm{BN}, \mathrm{RW}$, and DF performed RT-PCR experiments. DD, LM, and SK performed TUNEL Assay. NN, KB, and DF interpreted 
the data and wrote the manuscript. All authors critically revised the manuscript.

\section{FUNDING}

This work was funded by a Mayo Clinic Cardiovascular Team Science Award (NN, DF and CL), National Institutes of Health (NIH) grant TL1 TR002380 (DD) and National Institute of Allergy and Infectious Disease (NIAID) grants R21 AI145356,

\section{REFERENCES}

1. Drafts BC, Twomley KM, D’Agostino R. Jr., Lawrence J, Avis N, Ellis LR, et al. Low to moderate dose anthracycline-based chemotherapy is associated with early noninvasive imaging evidence of subclinical cardiovascular disease. JACC Cardiovasc Imaging. (2013) 6:877-85. doi: 10.1016/j.jcmg.2012.11.017

2. Lipshultz SE, Adams MJ. Cardiotoxicity after childhood cancer: beginning with the end in mind. J Clin Oncol. (2010) 28:127681. doi: 10.1200/JCO.2009.26.5751

3. Lipshultz SE, Lipsitz SR, Sallan SE, Dalton VM, Mone SM, Gelber RD, et al. Chronic progressive cardiac dysfunction years after doxorubicin therapy for childhood acute lymphoblastic leukemia. J Clin Oncol. (2005) 23:262936. doi: 10.1200/JCO.2005.12.121

4. Plana JC. The red devil revisited. Jacc-Cardiovasc Imag. (2013) 6:8868. doi: 10.1016/j.jcmg.2013.04.009

5. Swain SM, Whaley FS, Ewer MS. Congestive heart failure in patients treated with doxorubicin: a retrospective analysis of three trials. Cancer. (2003) 97:2869-79. doi: 10.1002/cncr.11407

6. Von Hoff DD, Layard MW, Basa P, Davis HL Jr, Von Hoff AL, Rozencweig M, et al. Risk factors for doxorubicin-induced congestive heart failure. Ann Intern Med. (1979) 91:710-7. doi: 10.7326/0003-4819-91-5-710

7. Simunek T, Sterba M, Popelova O, Adamcova M, Hrdina R, Gersl V. Anthracycline-induced cardiotoxicity: overview of studies examining the roles of oxidative stress and free cellular iron. Pharmacol Rep. (2009) 61:15471. doi: 10.1016/S1734-1140(09)70018-0

8. Zhang S, Liu X, Bawa-Khalfe T, Lu LS, Lyu YL, Liu LF, et al. Identification of the molecular basis of doxorubicin-induced cardiotoxicity. Nat Med. (2012) 18:1639-42. doi: 10.1038/nm.2919

9. Zhou S, Starkov A, Froberg MK, Leino RL, Wallace KB. Cumulative and irreversible cardiac mitochondrial dysfunction induced by doxorubicin. Cancer Res. (2001) 61:771-7.

10. Lebrecht D, Kirschner J, Geist A, Haberstroh J, Walker UA. Respiratory chain deficiency precedes the disrupted calcium homeostasis in chronic doxorubicin cardiomyopathy. Cardiovasc Pathol. (2010) 19:e167-74. doi: 10.1016/j.carpath.2009.06.006

11. Zhou S, Heller LJ, Wallace KB. Interference with calciumdependent mitochondrial bioenergetics in cardiac myocytes isolated from doxorubicin-treated rats. Toxicol Appl Pharmacol. (2001) 175:60-7. doi: 10.1006/taap.2001.9230

12. Solem LE, Henry TR, Wallace KB. Disruption of mitochondrial calcium homeostasis following chronic doxorubicin administration. Toxicol Appl Pharmacol. (1994) 129:214-22. doi: 10.1006/taap.1994.1246

13. Zhao L, Zhang B. Doxorubicin induces cardiotoxicity through upregulation of death receptors mediated apoptosis in cardiomyocytes. Sci Rep. (2017) 7:44735. doi: 10.1038/srep44735

14. Bien S, Riad A, Ritter CA, Gratz M, Olshausen F, Westermann $\mathrm{D}$, et al. The endothelin receptor blocker bosentan inhibits doxorubicin-induced cardiomyopathy. Cancer Res. (2007) 67:1042835. doi: 10.1158/0008-5472.CAN-07-1344

15. Armenian SH, Lacchetti C, Barac A, Carver J, Constine LS, Denduluri N, et al. Prevention and monitoring of cardiac dysfunction in survivors of adult cancers: american society of clinical oncology clinical practice guideline. J Clin Oncol. (2017) 35:893-911. doi: 10.1200/JCO.2016.70.5400
R21 AI152318, R21 AI154927 and American Heart Association grant 20TPA35490415 (DF).

\section{ACKNOWLEDGMENTS}

The authors would like to thank the Dennis Dickson Histology Group for their work embedding and staining slides for this project. This group includes Dennis W. Dickson, Ph.D. Linda Rousseau, Virginia Phillips, Ariston Libraro and Monica Castanedes.

16. Deng S, Yan T, Jendrny C, Nemecek A, Vincetic M, Godtel-Armbrust $\mathrm{U}$, et al. Dexrazoxane may prevent doxorubicin-induced DNA damage via depleting both topoisomerase II isoforms. BMC Cancer. (2014) 14:842. doi: 10.1186/1471-2407-14-842

17. Hasinoff $\mathrm{BB}$, Patel $\mathrm{D}, \mathrm{Wu} \mathrm{X}$. The role of topoisomerase IIbeta in the mechanisms of action of the doxorubicin cardioprotective agent dexrazoxane. Cardiovasc Toxicol. (2019). 20:312-20. doi: 10.1007/s12012-019-09554-5

18. Swain SM, Whaley FS, Gerber MC, Weisberg S, York M, Spicer D, et al. Cardioprotection with dexrazoxane for doxorubicin-containing therapy in advanced breast cancer. J Clin Oncol. (1997) 15:131832. doi: 10.1200/JCO.1997.15.4.1318

19. Serie DJ, Crook JE, Necela BM, Dockter TJ, Wang X, Asmann YW, et al. Genome-wide association study of cardiotoxicity in the NCCTG N9831 (Alliance) adjuvant trastuzumab trial. Pharmacogenet Genomics. (2017) 10:378-85. doi: 10.1097/FPC.0000000000000302

20. Norton N, Crook JE, Wang L, Olson JE, Kachergus JM, Serie DJ, et al. Association of genetic variants at TRPC6 with chemotherapy-related heart failure. Front Cardiovasc Med. (2020) 7:142. doi: 10.3389/fcvm.2020.00142

21. Beech DJ. Characteristics of transient receptor potential canonical calciumpermeable channels and their relevance to vascular physiology and disease. Circ J. (2013) 77:570-9. doi: 10.1253/circj.CJ-13-0154

22. Polat OK, Uno $\mathrm{M}$, Maruyama $\mathrm{T}$, Tran $\mathrm{HN}$, Imamura $\mathrm{K}$, Wong $\mathrm{CF}$, et al. Contribution of Coiled-Coil Assembly to $\mathrm{Ca}(2+) /$ CalmodulinDependent Inactivation of TRPC6 Channel and its Impacts on FSGS-Associated Phenotypes. J Am Soc Nephrol. (2019) 30:1587-603. doi: 10.1681/ASN.2018070756

23. Numaga-Tomita T, Kitajima N, Kuroda T, Nishimura A, Miyano K, Yasuda $\mathrm{S}$, et al. TRPC3-GEF-H1 axis mediates pressure overload-induced cardiac fibrosis. Sci Rep. (2016) 6:39383. doi: 10.1038/srep39383

24. Seo K, Rainer PP, Shalkey Hahn V, Lee DI, Jo SH, Andersen A, et al. Combined TRPC3 and TRPC6 blockade by selective small-molecule or genetic deletion inhibits pathological cardiac hypertrophy. Proc Natl Acad Sci U S A. (2014) 111:1551-6. doi: 10.1073/pnas.1308963111

25. Seth M, Zhang ZS, Mao L, Graham V, Burch J, Stiber J, et al. TRPC1 channels are critical for hypertrophic signaling in the heart. Circ Res. (2009) 105:1023-30. doi: 10.1161/CIRCRESAHA.109.206581

26. Dietrich A, Mederos YSM, Gollasch M, Gross V, Storch U, Dubrovska $\mathrm{G}$, et al. Increased vascular smooth muscle contractility in TRPC6-/mice. Mol Cell Biol. (2005) 25:6980-9. doi: 10.1128/MCB.25.16.6980-6989. 2005

27. Abston ED, Barin JG, Cihakova D, Bucek A, Coronado MJ, Brandt JE, et al. IL-33 independently induces eosinophilic pericarditis and cardiac dilation: ST2 improves cardiac function. Circ Heart Fail. (2012) 5:36675. doi: 10.1161/CIRCHEARTFAILURE.111.963769

28. Abston ED, Coronado MJ, Bucek A, Bedja D, Shin J, Kim JB, et al. Th2 regulation of viral myocarditis in mice: different roles for TLR3 versus TRIF in progression to chronic disease. Clin Dev Immunol. (2012) 2012:129486. doi: 10.1155/2012/129486

29. Bruno KA, Mathews JE, Yang AL, Frisancho JA, Scott AJ, Greyner $\mathrm{HD}$, et al. BPA alters estrogen receptor expression in the heart after viral infection activating cardiac mast cells and $\mathrm{T}$ cells leading to perimyocarditis and fibrosis. Front Endocrinol (Lausanne). (2019) 10:598. doi: $10.3389 /$ fendo.2019.00598 
30. Coronado MJ, Bruno KA, Blauwet LA, Tschope C, Cunningham MW, Pankuweit S, et al. Elevated Sera sST 2 Is Associated With Heart Failure in Men $</=50$ years old with myocarditis. J Am Heart Assoc. (2019) 8:e008968. doi: 10.1161/JAHA.118.008968

31. Fairweather D, Frisancho-Kiss S, Njoku DB, Nyland JF, Kaya Z, Yusung SA, et al. Complement receptor 1 and 2 deficiency increases coxsackievirus B3induced myocarditis, dilated cardiomyopathy, and heart failure by increasing macrophages, IL-1beta, and immune complex deposition in the heart. $J$ Immunol. (2006) 176:3516-24. doi: 10.4049/jimmunol.176.6.3516

32. Fairweather D, Frisancho-Kiss S, Yusung SA, Barrett MA, Davis SE, Gatewood SJ, et al. Interferon-gamma protects against chronic viral myocarditis by reducing mast cell degranulation, fibrosis, and the profibrotic cytokines transforming growth factor-beta 1, interleukin-1 beta, and interleukin-4 in the heart. Am J Pathol. (2004) 165:1883-94. doi: 10.1016/S0002-9440(10)63241-5

33. Radonic A, Thulke S, Mackay IM, Landt O, Siegert W, Nitsche A. Guideline to reference gene selection for quantitative real-time PCR. Biochem Biophys Res Commun. (2004) 313:856-62. doi: 10.1016/j.bbrc.2003.11.177

34. Livak KJ, Schmittgen TD. Analysis of relative gene expression data using realtime quantitative PCR and the 2(-Delta Delta C(T)) Method. Methods. (2001) 25:402-8. doi: 10.1006/meth.2001.1262

35. Miyata S, Minobe W, Bristow MR, Leinwand LA. Myosin heavy chain isoform expression in the failing and nonfailing human heart. Circ Res. (2000) 86:38690. doi: 10.1161/01.RES.86.4.386

36. Nakao K, Minobe W, Roden R, Bristow MR, Leinwand LA. Myosin heavy chain gene expression in human heart failure. J Clin Invest. (1997) 100:236270. doi: 10.1172/JCI119776

37. Boluyt MO, O'Neill L, Meredith AL, Bing OH, Brooks WW, Conrad $\mathrm{CH}$, et al. Alterations in cardiac gene expression during the transition from stable hypertrophy to heart failure. Marked upregulation of genes encoding extracellular matrix components. Circ Res. (1994) 75:23-32. doi: 10.1161/01.RES.75.1.23

38. Mercadier JJ, Lompre AM, Wisnewsky C, Samuel JL, Bercovici J, Swynghedauw B, et al. Myosin isoenzyme changes in several models of rat cardiac hypertrophy. Circ Res. (1981) 49:525-32. doi: 10.1161/01.RES.49.2.525

39. Kitajima N, Numaga-Tomita $T$, Watanabe $M$, Kuroda $T$, Nishimura A, Miyano K, et al. TRPC3 positively regulates reactive oxygen species driving maladaptive cardiac remodeling. Sci Rep. (2016) 6:37001. doi: 10.1038/srep37001

40. Kuwahara K, Wang Y, McAnally J, Richardson JA, Bassel-Duby R, Hill JA, et al. TRPC6 fulfills a calcineurin signaling circuit during pathologic cardiac remodeling. J Clin Invest. (2006) 116:3114-26. doi: 10.1172/JCI27702

41. Suchyna TM. Piezo channels and GsMTx4: Two milestones in our understanding of excitatory mechanosensitive channels and their role in pathology. Prog Biophys Mol Biol. (2017) 130(Pt B):244-53. doi: 10.1016/j.pbiomolbio.2017.07.011

42. Spassova MA, Hewavitharana T, Xu W, Soboloff J, Gill DL. A common mechanism underlies stretch activation and receptor activation of TRPC6 channels. Proc Natl Acad Sci U S A. (2006) 103:16586-91. doi: 10.1073/pnas.0606894103

43. Kitajima N, Watanabe K, Morimoto S, Sato Y, Kiyonaka S, Hoshijima M, et al. TRPC3-mediated Ca2+ influx contributes to Rac1-mediated production of reactive oxygen species in MLP-deficient mouse hearts. Biochem Biophys Res Commun. (2011) 409:108-13. doi: 10.1016/j.bbrc.2011.04.124

44. Shimauchi T, Numaga-Tomita T, Ito T, Nishimura A, Matsukane R, Oda S, et al. TRPC3-Nox2 complex mediates doxorubicin-induced myocardial atrophy. JCI Insight. (2017) 2:e93358. doi: 10.1172/jci.insight.93358

45. Oda S, Numaga-Tomita T, Kitajima N, Toyama T, Harada E, Shimauchi T, et al. TRPC6 counteracts TRPC3-Nox2 protein complex leading to attenuation of hyperglycemia-induced heart failure in mice. Sci Rep. (2017) 7:7511. doi: 10.1038/s41598-017-07903-4

46. Matthews AT, Soni H, Robinson-Freeman KE, John TA, Buddington RK, Adebiyi A. Doxorubicin-induced fetal mesangial cell death occurs independently of TRPC6 channel upregulation but involves mitochondrial generation of reactive oxygen species. Int J Mol Sci. (2021) 22:7589. doi: 10.3390/ijms22147589

47. da Silva JS, Montagnoli TL, Rocha BS, Tacco M, Marinho SCP, ZapataSudo G. Estrogen receptors: therapeutic perspectives for the treatment of cardiac dysfunction after myocardial infarction. Int J Mol Sci. (2021) 22:525. doi: 10.3390/ijms22020525

48. Fairweather D, Cooper LT Jr, Blauwet LA. Sex and gender differences in myocarditis and dilated cardiomyopathy. Curr Probl Cardiol. (2013) 38:746. doi: 10.1016/j.cpcardiol.2012.07.003

49. Firth JM, Yang HY, Francis AJ, Islam N, MacLeod KT. The effect of estrogen on intracellular $\mathrm{Ca}(2+)$ and $\mathrm{Na}(+)$ regulation in heart failure. JACC Basic Transl Sci. (2020) 5:901-12. doi: 10.1016/j.jacbts.2020.06.013

50. Pedram A, Razandi M, Aitkenhead M, Levin ER. Estrogen inhibits cardiomyocyte hypertrophy in vitro. Antagonism of calcineurin-related hypertrophy through induction of MCIP1. J Biol Chem. (2005) 280:2633948. doi: 10.1074/jbc.M414409200

51. Sabbatini AR, Kararigas G. Estrogen-related mechanisms in sex differences of hypertension and target organ damage. Biol Sex Differ. (2020) 11:31. doi: 10.1186/s13293-020-00306-7

52. Virani SS, Alonso A, Aparicio HJ, Benjamin EJ, Bittencourt MS, Callaway CW, et al. Heart disease and stroke statistics-2021 update: a report from the american heart association. Circulation. (2021) 143:e254-743. doi: 10.1161/CIR.0000000000000950

53. Advani PP, Ballman KV, Dockter TJ, Colon-Otero G, Perez EA. Long-term cardiac safety analysis of NCCTG N9831 (Alliance) adjuvant trastuzumab trial. J Clin Oncol. (2016) 34:581-7. doi: 10.1200/JCO.2015.61.8413

54. Romond EH, Jeong JH, Rastogi P, Swain SM, Geyer CE Jr, Ewer MS, et al. Seven-year follow-up assessment of cardiac function in NSABP B-31, a randomized trial comparing doxorubicin and cyclophosphamide followed by paclitaxel (ACP) with ACP plus trastuzumab as adjuvant therapy for patients with node-positive, human epidermal growth factor receptor 2-positive breast cancer. J Clin Oncol. (2012) 30:3792-9. doi: 10.1200/JCO.2011.40.0010

55. Dickinson JM, D'Lugos AC, Mahmood TN, Ormsby JC, Salvo L, Dedmon WL, et al. Exercise protects skeletal muscle during chronic doxorubicin administration. Med Sci Sports Exerc. (2017) 49:2394-403. doi: 10.1249/MSS.0000000000001395

56. Flores-Soto E, Reyes-Garcia J, Carbajal-Garcia A, Campuzano-Gonzalez E, Perusquia M, Sommer B, et al. Sex steroids effects on guinea pig airway smooth muscle tone and intracellular $\mathrm{Ca}(2+)$ basal levels. Mol Cell Endocrinol. (2017) 439:444-56. doi: 10.1016/j.mce.2016.10.004

57. Kalidhindi RSR, Katragadda R, Beauchamp KL, Pabelick CM, Prakash YS, Sathish V. Androgen receptor-mediated regulation of intracellular calcium in human airway smooth muscle cells. Cell Physiol Biochem. (2019) 53:21528. doi: 10.33594/000000131

58. Ronnekleiv OK, Zhang C, Bosch MA, Kelly MJ. Kisspeptin and gonadotropin-releasing hormone neuronal excitability: molecular mechanisms driven by 17beta-Estradiol. Neuroendocrinology. (2015) 102:184-93. doi: 10.1159/000370311

59. Wang S, Wang Y, Qiu K, Zhu J, Wu Y. RCAN1 in cardiovascular diseases: molecular mechanisms and a potential therapeutic target. Mol Med. (2020) 26:118. doi: 10.1186/s10020-020-00249-0

60. Camacho Londono JE, Tian Q, Hammer K, Schroder L, Camacho Londono J, Reil JC, et al. A background Ca2 + entry pathway mediated by TRPC1/TRPC4 is critical for development of pathological cardiac remodelling. Eur Heart J. (2015) 36:2257-66. doi: 10.1093/eurheartj/ehv250

61. Chang AS, Chang SM, Garcia RL, Schilling WP. Concomitant and hormonally regulated expression of trp genes in bovine aortic endothelial cells. FEBS Lett. (1997) 415:335-40. doi: 10.1016/S0014-5793(97)01155-1

62. Tran QK. Reciprocality between estrogen biology and calcium signaling in the cardiovascular system. Front Endocrinol (Lausanne). (2020) 11:568203. doi: 10.3389/fendo.2020.568203

63. Norton N, Necela BM, Wang XL, Lu T, Lee HC. TRPC6 gain-of-function in doxorubicin-induced heart failure. Am Soc Hum Genet Meet. (2021) 1822 Virtual.

64. Chinigo G, Fiorio Pla A, Gkika D. TRP channels and small GTPases interplay in the main hallmarks of metastatic cancer. Front Pharmacol. (2020) 11:581455. doi: 10.3389/fphar.2020.581455

65. Chigurupati S, Venkataraman R, Barrera D, Naganathan A, Madan M, Paul L, et al. Receptor channel TRPC6 is a key mediator of Notchdriven glioblastoma growth and invasiveness. Cancer Res. (2010) 70:41827. doi: 10.1158/0008-5472.CAN-09-2654 
66. Jardin I, Diez-Bello R, Lopez JJ, Redondo PC, Salido GM, Smani T, et al. TRPC6 channels are required for proliferation, migration and invasion of breast cancer cell lines by modulation of orail and orai3 surface exposure. Cancers (Basel). (2018) 10:331. doi: 10.3390/cancers10090331

Conflict of Interest: The authors declare that the research was conducted in the absence of any commercial or financial relationships that could be construed as a potential conflict of interest.

Publisher's Note: All claims expressed in this article are solely those of the authors and do not necessarily represent those of their affiliated organizations, or those of the publisher, the editors and the reviewers. Any product that may be evaluated in this article, or claim that may be made by its manufacturer, is not guaranteed or endorsed by the publisher.

Copyright (๑ 2022 Norton, Bruno, Di Florio, Whelan, Hill, Morales-Lara, Mease, Sousou, Malavet, Dorn, Salomon, Macomb, Khatib, Anastasiadis, Necela, McGuire, Giresi, Kotha, Beetler, Weil, Landolfo and Fairweather. This is an open-access article distributed under the terms of the Creative Commons Attribution License (CC BY). The use, distribution or reproduction in other forums is permitted, provided the original author(s) and the copyright owner(s) are credited and that the original publication in this journal is cited, in accordance with accepted academic practice. No use, distribution or reproduction is permitted which does not comply with these terms. 